\title{
The Institute of Advancing Medical Innovation (IAMI): Stepping into the future of academic research and entrepreneurship
}

\author{
G. Sitta Sittampalam \\ Professor and Deputy Director of IAMI, University of Kansas Medical Center \\ Scott Weir \\ Professor and Director of IAMI, University of Kansas Medical Center \\ Michael Hughes \\ Program Director of IAMI, University of Kansas Medical Center
}

he Institute for Advancing Medical Innovations (IAMI) was founded in
January 2009 with an $\$ 8.1$ million funding from the Kauffman foundation and
a matching contribution from the University of Kansas Endowment Association. The \$16.2 million funding for five years was targeted to: 1 ) advance novel, new medical innovations for the diagnosis, treatment, prevention and control of human and animal disease to clinical proof of concept, 2) create a culture of multidisciplinary, multi-organizational collaboration, and 3) prepare graduate and postdoctoral student for careers in development and commercialization of medical innovations. A staff of experienced project managers and management with over 100 years of pharmaceutical industry experience, and an external advisory board of experienced entrepreneurs and an adjunct faculty to mentor graduate fellows supports IAMI. Annual investment of $\$ 1.6$ million is for proof-of concept (POC) projects initiated by KU faculty both at the Lawrence campus and the medical center in Kansas City. This investment is intended as a key differentiator for the National Cancer Institute (NCI) designation for the University of Kansas Cancer Center and the Clinical Translational Science Award currently under preparation.

\section{Introduction}

Academic research in science and technology has been one of the main drivers in economic development, prosperity and dramatic improvement in public health in the developed countries. This is particularly evident in the $20^{\text {th }}$ century United States with the discovery of the transistors, microelectronics, microcomputers and the Internet in the telecommunications arena. In health sciences, the development of polio vaccine, antibiotics, and the advent of molecular biology, DNA structure, human genome and innovations in medical devices have revolutionized public health. Much of this discovery and development effort has strong roots in the basic science and technology research actively supported by the 
government and the universities. For example, the development of the Silicon Valley and the biotech industries in California, Massachusetts, Washington, North Carolina and other states, are located around strong academic communities that promote venture capital and start up companies that have flourished since the 1950s.

The Institute for Advancing Medical Innovations (IAMI) currently in place at the University of Kansas (KU) is a bold step in this direction to promote translational research by the faculty and students which will contribute strongly to the economic development in Kansas and the Kansas City region. We anticipate that this effort in partnership with the Kauffman Foundation, Kansas Biosciences Authority (KBA) and regional animal and bioscience industry will promote entrepreneurship and economic development.

As shown in Figure 1, IAMI supports Proof-of-Concept (POC) projects in drug discovery and delivery along with innovative approaches to drug-device development that can lead to commercialization through start up companies based on research funded at KU. Partnerships will be entertained and encouraged with national and international universities, companies and philanthropic organizations to deliver life-saving products to patients. Revenues from these activities will be used to fund translational research at $\mathrm{KU}$ and in the Kansas City region. As part of this effort, IAMI will provide training and mentoring for faculty and students on entrepreneurship, business development, intellectual property management and venture funding in collaboration with the KU Business School and the University of Kansas Center for Technology Commercialization (KUCTC).

Proof-of-Concept Projects:

IAMI and the Kauffmann foundation, the largest non-profit organization that supports entrepreneurship, intended that the

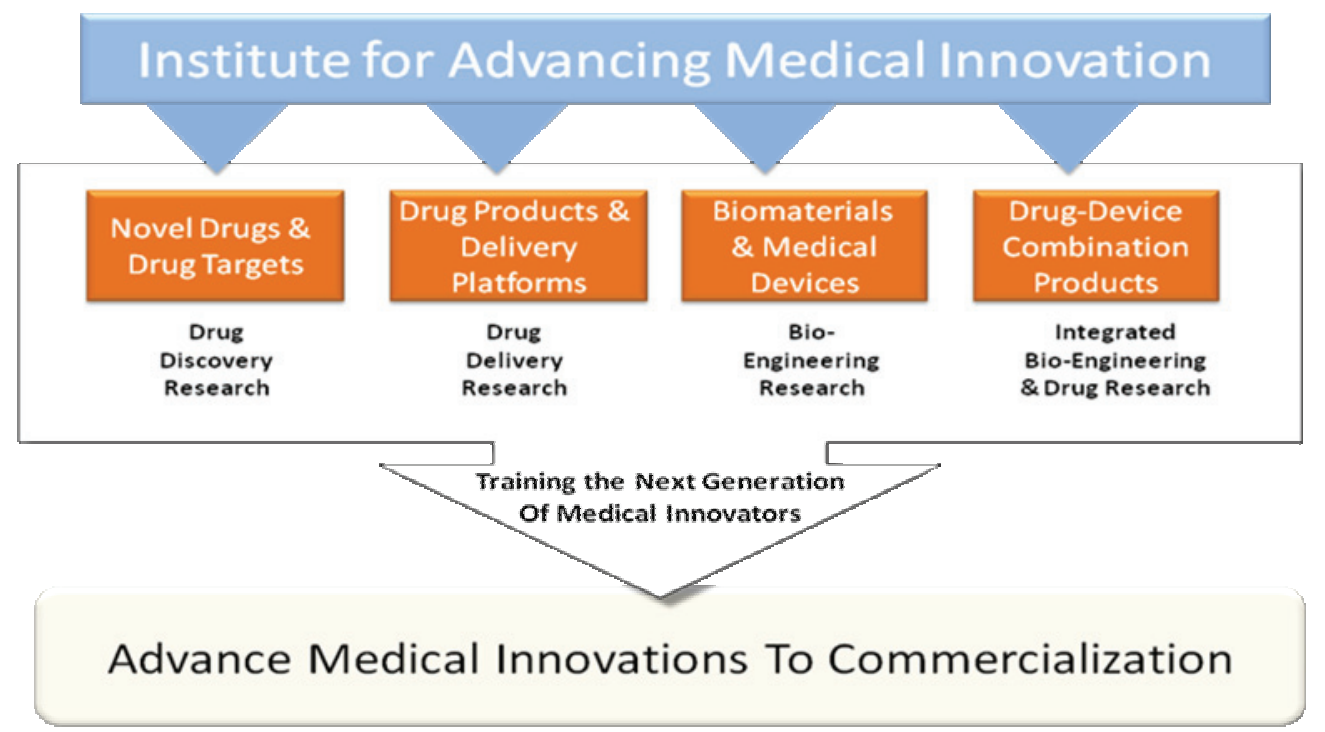

Figure 1: Functional architecture of IAMI 


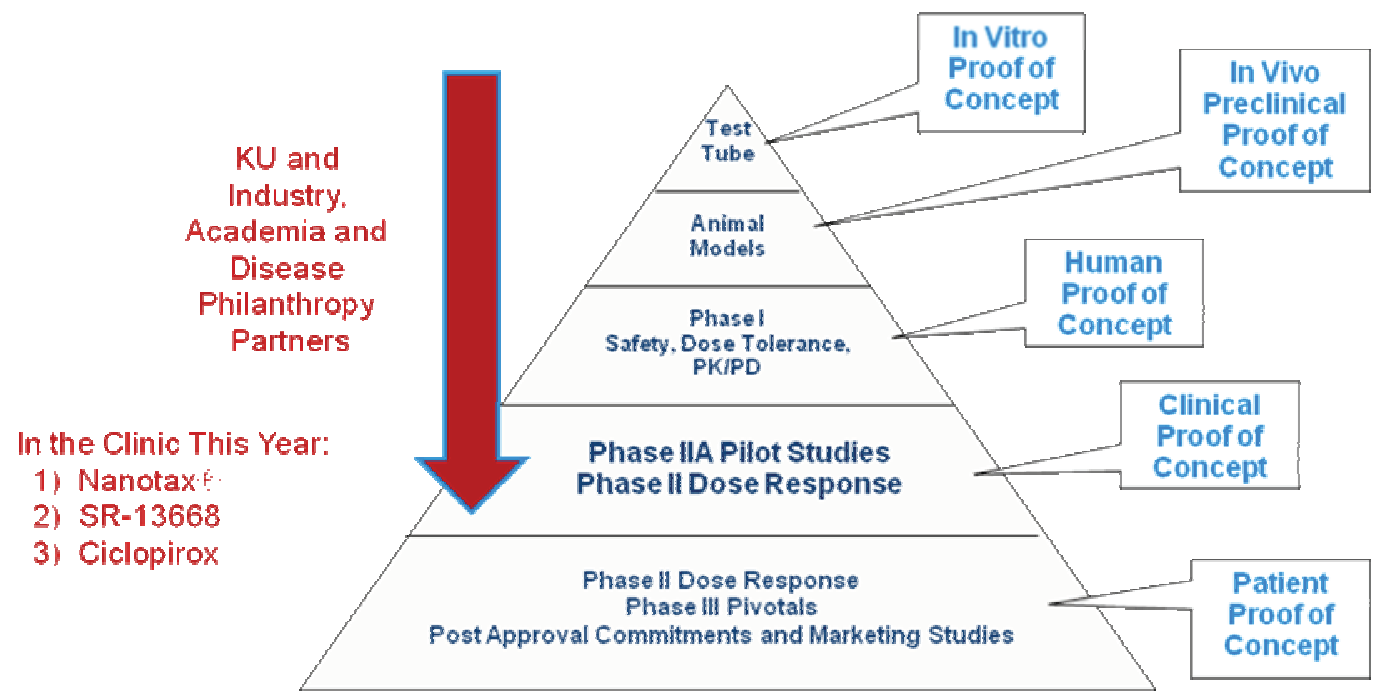

Figure 2: The Discovery and Development Pyramid

funds would leverage translational projects derived from federal research dollars to KU. The annual \$16 million funding will be for five years to support POC projects.

Figure 2 illustrates an idea that starts on pieces of paper and a test tube on the basis of basic science research supported by federal and philanthropic research grants. Scientists drive these ideas and projects through various stages of early development that mostly result in significant scientific publications and serve to train students and post-doctoral scientists. Many of the discoveries, when carefully evaluated, may have benefit for patients and the public and require rigorous research development activities before commercialization. Work needs to be done in in-vivo animal studies and then in expensive human clinical trials with appropriate product type (formulation, device etc.) to advance discoveries to the patients and the public.

In the past, this aspect of translational research is generally not funded by federal agencies or philanthropic research organizations, but carried out by multinational corporations and biotechnology companies based on academic publications. Lack of such support resulted in lost economic opportunities for the universities, academic researchers and the region- generally identified as the "Valley of Death" for the projects that have commercial potential. The projects at this stage are too early for venture capital investment and too advanced for basic research funding. IAMI targets the translational research activities with specific milestone-based funding and project management support from industry experienced project managers and adjunct faculty.

Note that prior to the establishment of IAMI, the Office of Therapeutics and Drug Development (OTDD) lead by Dr. Scott Weir promoted three projects that are in the clinic as shown in Figure 2. Nanotax ${ }^{\circledR}$ is nano-crystalline form of Paclitaxel for ovarian cancer that is currently in Phase I at the University of Kansas Cancer Center, and was a KU innovation to minimize side effects in the current marketed formulation. The Ciclopirox Olamine is a project to support a blood cancer therapy with the 
National Leukemia Lymphoma Society and the University of Toronto, Princess Margaret hospital, while SR-13668 is a collaborative project with the Mayo Clinic for cancer prevention. We have several other projects with Children's Mercy Hospital in Kansas City and the Institute of Pediatric Innovation in Boston, on translational projects bringing innovative drugs and formulations for pediatric patients.

The requirements for selecting POC projects are shown in Table 1. Once the request for proposals (RFP) are announced within $\mathrm{KU}$, principal investigators and students submit a letter of intent (LOI) to IAMI and meet with project managers to plan the preparation of the grant proposals. Note that the criteria described in the Table below strongly encourage applicants to submit relevant information on their science, technology, intellectual property and commercialization potential. These proposals are, therefore, quite different from other basic science grant applications. Both the faculty and students learn many aspects of innovation and commercialization that are not part of normal university curriculum.

\begin{tabular}{|l|}
\hline$\cdot$ Medical innovation novelty (unmet need) \\
\hline$\cdot$ Potential market size \\
\hline$\cdot$ Market definition \\
\hline$\cdot$ Medical innovation maturity \\
\hline$\cdot$ Utility of proof of concept funding \\
\hline - Intellectual property position \\
\hline - Principal investigator credibility \\
\hline
\end{tabular}

Table 1: POC Criteria: Project objectives, go/no go decision points, and detailed project plans are required for funding consideration.
The full applications are reviewed by the IAMI advisory board that consists of nationally and internationally recognized leaders in translational pharmaceutical research, device development and venture investments in start up companies (Table 2). Since early 2009, twenty-five (25) POC projects have been funded at an investment commitment of \$3.2 $\mathrm{M}$ to KU investigators in two review cycles.

\begin{tabular}{l} 
Christopher P. Austin, Director, National Institutes \\
of Health Chemical Genomics Center \\
Steven D. Averbuch, Vice President, Oncology \\
Global Clinical Research, Bristol-Myers Squibb \\
Company \\
Michael D. Webb, Executive Chairman, Virtify, Inc. \\
Anand C. Burman, Chairman of the Board, Dabur \\
India Limited, New Delhi, India \\
\hline David Vranicar, President, Heartland Bioventures, \\
Kansas Bioscience Authority \\
\hline David Jenkins, Managing Partner, FatBoy Capital, \\
L.P. \\
\hline Thomas Wiggans, former Chief Executive Officer \\
and Chairman of the Board, Peplin, Inc.
\end{tabular}

Table 2: The IAMI advisory Board and their affiliations. All but Dr. Austin are KU alums with successful careers in biotechnology and medical device industries.

\section{IAMI Fellows Training Program}

As part of its commitment to the educational mission of the university and training entrepreneurs, IAMI funds fellowships for 10 graduate students and 4 post-doctoral scientists at $\mathrm{KU}$ on an yearly basis. One additional post-doctoral scientist is funded at the Kauffman National Fellowships program through IAMI. The Fellows come from business school, chemistry, biology, engineering and related programs at $\mathrm{KU}$, and have projects that are innovative. They are required to attend regular group meetings, meet with assigned adjunct instructors as 
mentors (Table 3), and submit annual progress reports to the IAMI management and the advisory board. They are required to work with KU Business School to develop business plans and funding proposals for venture capital firms. This is a unique opportunity for the IAMI fellows to develop their science and technology and conceptualize their business plans.

\begin{tabular}{|l|}
\hline Mike Baltezor (Formerly Enturia Inc, a Cardinal \\
Health company, Kansas City, KS.) \\
\hline $\begin{array}{l}\text { Andrew Parkinson (Xenotech, Kansas City, } \\
\text { KS) }\end{array}$ \\
\hline Tony Barnes (Rules Based Medic, Austin, TX) \\
\hline John Neet (J.M. Neet \& Associates. Lawrence, \\
KS. \\
\hline Mike Beckloff (Beckloff Associates, a Cardinal \\
Health company, Kansas City KS.) \\
\hline Matt McClorey (Lawrence Regional \\
Technology, Lawrence, KS.) \\
\hline Tom Engler (Eli Lilly \& Co. Indianapolis, IN.) \\
\hline Ken Lynn (New Link Genetics, IA) \\
\hline Bo Fishback (Kauffman Foundation, Orbis \\
Pharmaceuticals Inc., Kansas City KS.) \\
\hline
\end{tabular}

Table 3: IAMI adjunct Instructors: experienced entrepreneurs from Kansas and around the country.

\section{The Ellis Family Seminar Series:}

Through a philanthropic contribution from a donor, the Ellis Family Symposium was inaugurated in 2010 at the KU Lawrence campus and the medical center campus in Kansas City. The seminars are open to the public and are intended to invite individuals from regional industry, universities, and research institutes to discuss innovation and commercialization concepts in their own experience. All fellows are required to attend the seminars and special engagements with the speakers are also scheduled before or after the seminars. These interactions are designed to encourage free flow of ideas and discussion between IAMI fellows and reputed entrepreneurs and business owners who are successful in their own right.

\section{Conclusions:}

Academic research supported by federal agencies such as the National Institutes of Health, National Science Foundation and philanthropic organizations have narrowly focused on basic and applied science and technology that results in publications and serves the educational missions of our universities. However, even after the Bayh-Dole act of 1980, there is very little funding or infrastructure that supports translational research and promotes entrepreneurship, commercialization and job creation. Traditionally, the discoveries from academia have been exploited by multinational corporations and biotech industries concentrated in a small number of regional centers. More and more local and state governments are recognizing job creation potential and its impact on economic development in their localities - IAMI is an example of this desire to exploit academic innovations.

IAMI is an innovative idea to support faculty entrepreneurs and local and regional economy by leveraging industrial expertise to commercialize discoveries at KU. As shown in Figure 3, by encouraging partnerships between researchers at both campuses and providing project management expertise, process re-engineering and training, we are fostering a culture of collaboration and innovation. An ultimate challenge in creating such 
models in the academic environment is its impact on the local and national its sustainability over the long term and economies.

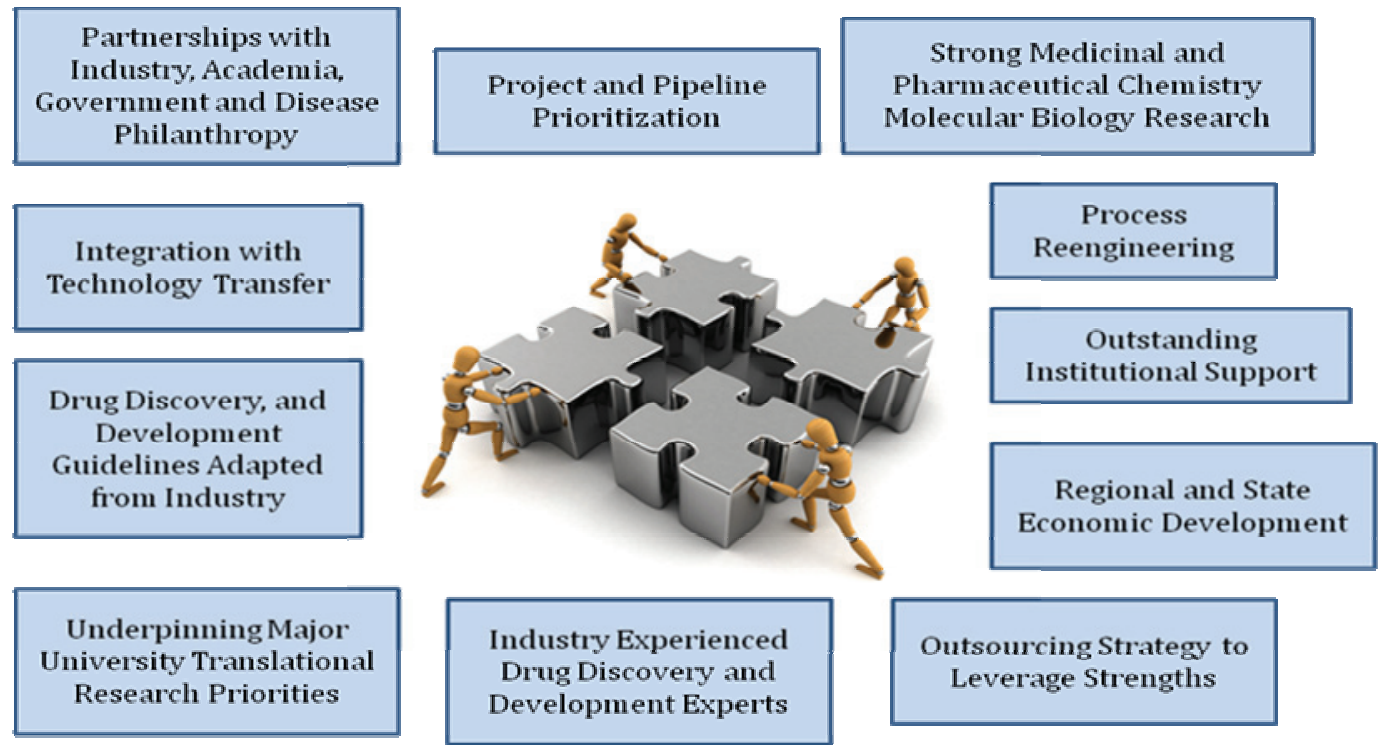

Figure 3: Transforming Federally Funded Research into medical innovations

Useful References:

P.L. 96-517, Patent and Trademark Act

Amendments of 1980.

http://www.access.gpo.gov/nara/cfr/waisidx 02/37 cfr401 02.html.

Merrill SA, Mazza AM (Editors) “Managing

University Intellectual Property in the Public
Interest". Committee on Science, Technology, and Law Policy and Global Affairs, National Research Council, National Academies Press. October 5, 2010. 